\title{
ENGLISH LANGUAGE ASSESSMENT IN MALAYSIA: TEACHERS' PRACTICES IN TEST PREPARATION
}

\author{
Looi-Chin Ch'ng ${ }^{1}$ \\ Soubakeavathi Rethinasamy ${ }^{2}$ \\ 'Universiti Teknologi Mara, Sarawak Campus \\ ${ }^{2}$ Centre for Language Studies, Universiti Malaysia Sarawak \\ ${ }^{1}$ chngl026@sarawak.uitm.edu.my \\ ${ }^{2}$ rsouba@cls.unimas.my
}

\begin{abstract}
In the context of English language teaching, many studies that claimed to investigate teachers' assessment practices were actually exploring their perceptions and belief with little reference to what they were practising in schools. The need to address such a limitation has prompted this study to examine the current formal assessment practices of English language teachers in lower secondary schools. Specifically, this paper reports how the teachers prepare the formal assessments. Extensive structured interviews were conducted with 72 teachers from 24 schools in Kuching division, Sarawak. Relevant documents such as test papers and assessment guidelines were also collected for further analysis. The findings from this study revealed that a majority of the teachers conducted formal assessments mainly due to the requirements of the school and ministry while following pre-determined steps in preparing a test. Furthermore, the findings also revealed teachers' reliance on commercial reference books in constructing exam questions and sample answers. The outcome of the study provides an insight on the nature of English language teachers' assessment practices in relation to the classroom teaching and learning at the secondary level.This could help inform the Ministry of Education in providing necessary support for the teachers particularly assessment practices in ESL context as well as in formulating a better assessment policy for schools.
\end{abstract}

Keywords: English language assessment, assessment practices, language testing

\section{Introduction}

Assessment is generally defined as the collection and interpretation of information through a process of synthesising, evaluating and passing judgement in decision making (Airasian, 2005). Specifically, it may also be seen as an everyday, on-going part of teaching and learning in the classroom. Smith (2001) stated that assessment is the set of processes through which inferences are made about learner's learning process, skills, knowledge and achievements. There is also a changing trend as to 
how assessments are used in education. Assessments are now widely administered as means to improve teaching and learning. Cizek and Fitzgerald (1996), for example, mention how teachers begin to realise the importance of using assessment for instructional purposes, in which the information gathered from the students' performance in a specific test is used to inform their pedagogical needs. Teachers therefore could identify necessary adjustments that need to be made in order to ensure students are able to master what has been taught. Nevertheless, it is argued that the use of assessment as a tool in teaching and learning largely depends on teachers' practices (Cumming, 2001; Mertle, 2005) and their understanding of the national standards (Poskitt \& Mitchell, 2012).

Assessment practices cover the steps and procedures taken by teachers throughout an assessment. These steps include preparing, administering and grading of an assessment as well as the recording and reporting of assessment results. Previous studies on teachers' assessment practices have been mostly directed toward identifying the important steps involved in forming effective assessments. Black and William (1998) suggested several practices that could help improve learning, which included enhancing feedback, actively involving students in their learning, adjusting instruction and re-teaching, and engaging students in self and peer-assessment activities. There are however several procedures or steps that many teachers are not competent in. The study by Mertle (2005), for example, revealed that teachers faced problems in preparing a test and developing valid grading procedures. Cizek and Fitzgerald (1996) also discovered that teachers had the tendency to ignore the importance of test preparation by doing what they think is right rather than what is right. Malone (2013), on the other hand, highlighted the need to increase teachers' assessment literacy in order to monitor students' progress. Hence, this paper reports on the study conducted to examine this issue by focusing mainly on the practices of English language teachers in preparing tests in secondary school.

\section{Background of the Study}

Since assessment is considered pivotal in the teaching and learning process, teachers are required to base their decisions (instructional, grading, and reporting) on some knowledge of student attainment of and progress towards desired learning outcomes (Cheng, Rogers, \& Hu, 2004; Guskey \& Bailey, 2001). In general, several studies on teachers' assessment practices in schools particularly in United States (Bailey, 2004; Yueming, Eslami, \& Burlbaw, 2006) have shown that a majority of the teachers valued assessments as an instructional tool that provides benefits to their students. Equally, as part of their professional practice, teachers are always involved in the observation of their learners, which leads to the development of insights about learner progress and judgements about specific learning outcomes and overall performance (Alderson \& Banerjee as cited in Rea-Dickins, 2004, p. 249).

In the context of English language teaching, many studies that claimed to investigate teachers' assessment practices were actually exploring teachers' perceptions as a whole. For example, a comparative study by Cheng et al. (2004), which involved 267 English as a Second Language (ESL) instructors at tertiary levels 
in Canada, Hong Kong and China was conducted to check on teachers' views on proper assessment practices. Though the results showed that the teachers mainly used assessment to inform instruction, the study did not consider whether the teachers were actually practising what they preached or viewed, or utilised the results for.

Replicating Cheng et al.'s (2004) study, Lee (2009) examined what and how teachers from middle and high schools in Korea assess students in their English language classrooms. The study involved 353 teachers from two schools and they were required to provide responses to a given questionnaire. The findings showed that the teachers from the two school settings demonstrated a similar pattern in purposes and procedures of assessment probably because of several substantial differences in their personal teaching history and educational settings which could have contributed to the similarities in their assessment decision-making. Some meaningful differences were also found in methods of assessment, favouring middle school teachers' constructive and effortful try-outs. Lee (2009) suggested the use of a more qualitative research method in uncovering teachers' assessment practices as the data collected from self-reported questionnaire may be biased and insufficient.

Previous studies discussed earlier focus mainly on instructors at tertiary level. As for ESL teachers in secondary schools, little is known about their assessment strategies Furthermore, the studies highlighted were conducted in foreign countries and the nature of teacher's assessment practices in Malaysia has yet to be well-documented and should be further explored. Studies related to language testing and assessment in Malaysian settings often focused on the strategies used by the ESL teachers in assessing specific language skills particularly writing and speaking (Vengadasamy, 2002). Moreover, there is also a strong emphasis on the validity and reliability issues of test constructs and assessment criteria and its resulting guidelines in constructing test papers and marking scheme (Khemlani-David, 1992). Limited studies have been conducted with regards to ESL teachers' assessment practices on the whole. There is a need to investigate further on ESL teachers' assessment practices as it would provide valuable input on the improvement of teaching and learning process. It is, thus, timely to gain a clear and overall understanding of what assessment practices are implemented by Malaysian English language teachers in schools. Thus, this paper examines what the teachers are currently practising in secondary school when it comes to test preparation. Assessment preparation is a very important step in ensuring that the assessment can achieve its intended goal or purpose. In the present study, the teachers were required to explain in detail on the process that they took or went through in preparing a test or an assessment. This covers the process from the initial stages of task delegation to finalisation and endorsement.

\section{Methodology}

For the purpose of the study, 24 schools were selected randomly out of the total of 31 government-funded national secondary schools (Sekolah Menengah Kebangsaan) in Kuching, Malaysia. In each school, three experienced English language teachers, one from each lower secondary form, with at least two years of teaching experience 
were randomly chosen to participate in the study. Teachers who were teaching more than one form in a particular school were assigned by the researcher to provide information only on one form based on their experiences in teaching the particular form. There were 72 teachers participating in this study. For the purpose of the study, the participants were sorted according to the forms that they were teaching and were labelled P1 (Form 1), P2 (Form 2) and P3 (Form 3) respectively. Then, each teacher within the form was assigned a letter from $A$ to $X$ (representing 24 participants) for identification.

Participants were interviewed at their preferred time. The audio-recording of each interview session lasted between 45 to 60 minutes. The whole data collection process took approximately four months to be completed in order to cover all the selected schools.

\section{Results and Discussions}

In preparing a specific formal assessment, the teachers usually go through five main stages, namely, task delegation, content decision, guidelines selection, resource selection and finalisation. The results from this study revealed the steps taken by the teacher in each stage.

\section{Task delegation}

In terms of task delegation, the teachers were first asked on delegation of test paper preparation tasks as shown in Figure 1.

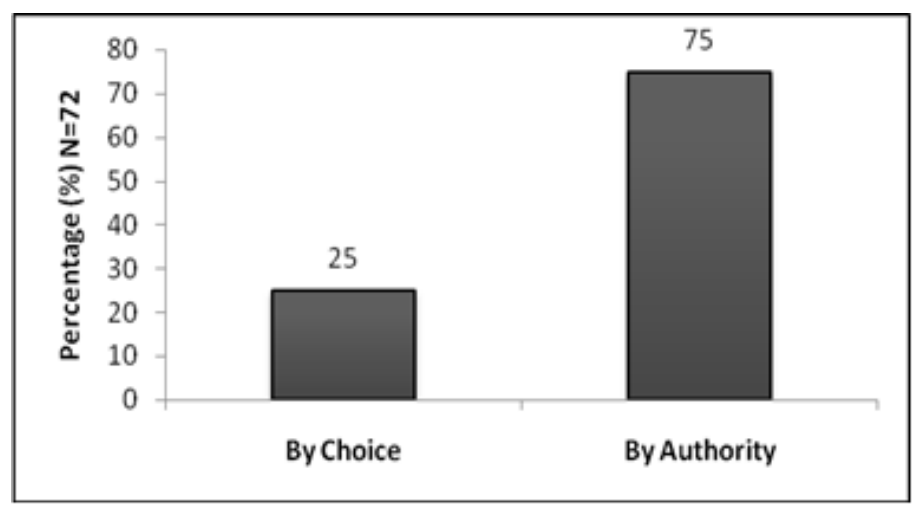

Figure 1. Delegation of assessment preparation tasks

A majority of the teachers $(75 \%, n=54)$ stated that they were assigned by a relevant authority (for example, the head of English panel) whereas $25 \%(n=18)$ of the them claimed to be assigned based on their choice. Based on the responses, it is evident that the teachers were assigned by the head of English panel to be in-charge of test paper preparation. Usually, they would know which test paper that they needed to prepare in a schooling year by referring to the "duty table" set by the head of panel. The "duty table" outlines clearly who is in charge of which test paper 
and the process normally involves all teachers teaching the subject as it is done in rotation as mentioned by $\mathrm{P} 1 \mathrm{~A}$ and $\mathrm{P} 2 \mathrm{~F}$ :

P1A: We are assigned by the head of English panel on the tasks for test preparation. It is normally done in rotation according to types of tests.

P2F: In my school, there is a "duty table" on who is in charge of a specific test. This is decided in our English panel meeting before [a schooling] year begins.

However, in some schools, teachers could volunteer to prepare a certain test especially topical and monthly tests. Instead of being directly assigned, the teachers had the liberty to decide during the English department meeting at the beginning of the year which test they wanted to prepare. The following excerpts by $\mathrm{P} 1 \mathrm{H}$ and $\mathrm{P} 3 \mathrm{U}$ illustrate this situation:

$\mathrm{P} 1 \mathrm{H}$ : I volunteered to prepare the test papers since we [teachers] are not assigned.

P3U: For monthly tests, I normally volunteered as I am comfortable with that. For other tests, the head of English panel decides.

Apart from knowing the instructions on task delegation, the teachers were asked about the mode of test preparations. Figure 2 shows the mode of test preparation as reported by the teachers.

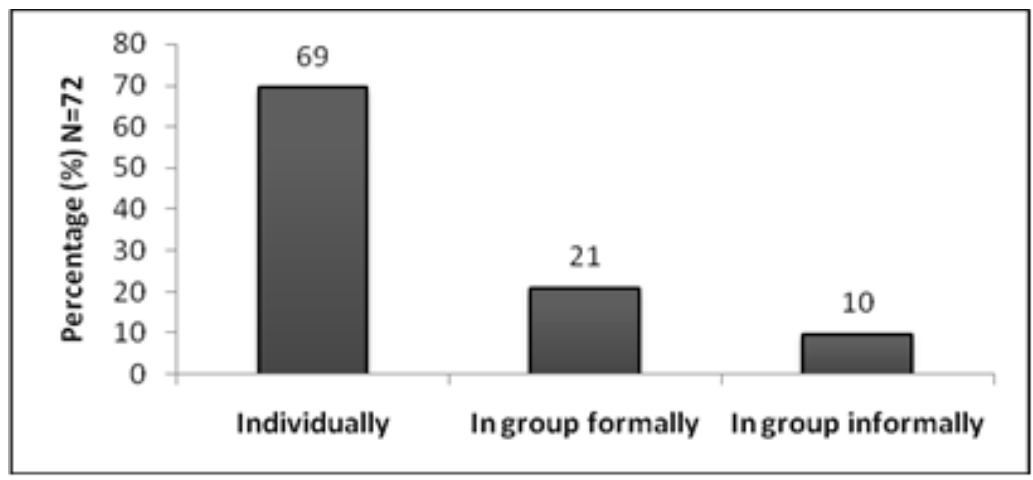

Figure 2. Mode of test preparation

Once assigned, the teachers normally prepare a particular test individually $(69 \%, n=50)$. However, teachers also prepare a test in group, $(31 \%, n=22)$ in order to gain more ideas and resources in preparing a test paper. When in groups, they either did it formally $(21 \%, n=15)$ or informally $(10 \%, n=7)$. A formal group involved discussions with the English panel and colleagues in a formal meeting while an informal group only involved discussions with colleagues in informal settings such as 
in the staff room or while having lunch at the canteen. P1T and P2H described these situations in the following excerpts:

P1T: In my school, I need to go through formal group meeting before every test construction. Discussions are done with the English panel (other English language teachers and the head of panel).

P2H: I normally discuss with my colleagues but informally, like when we meet after class.

Clearly, teachers had the freedom to decide whether to discuss the test preparation formally or informally. Lastly, in task delegation, the teachers were required to state which parts or sections of a paper that they were assigned to prepare as shown in Figure 3.

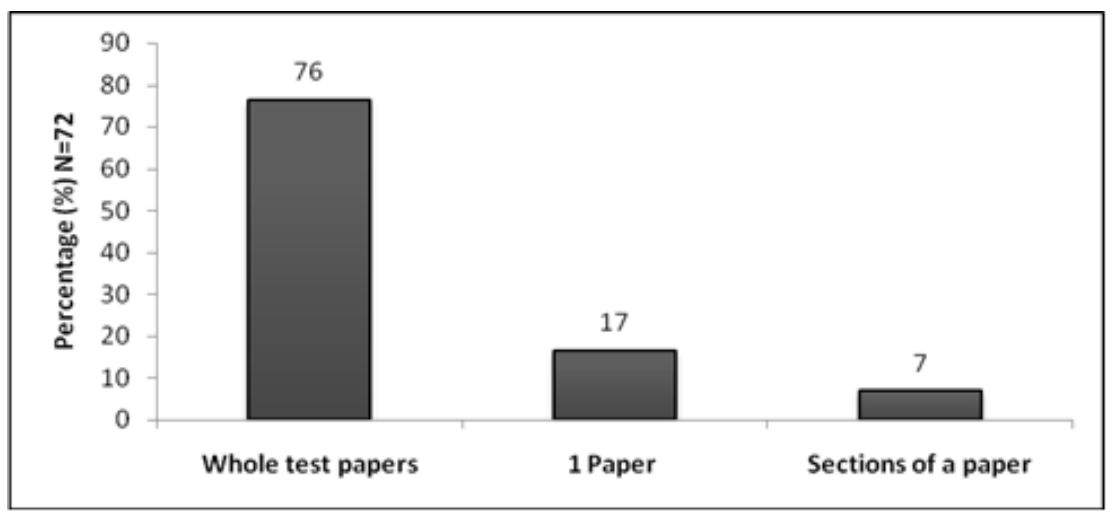

Figure 3. Parts or sections of a test paper assigned

In most schools, the teachers were assigned to prepare the whole test paper $(76 \%, n=55)$ particularly tests that had only one paper such as topical tests and monthly tests as revealed in the following excerpt by P1P:

P1P: In our school, most of the time we have two teachers to set test papers for mid-term and final. For monthly tests only one teacher is assigned to set the whole test paper because we only have one paper for monthly test unlike the major tests, have paper 1 and 2 .

However, in five schools, all formal assessments in Form 3 contained two test papers without taking into account whether they were major (i.e. mid-term, final, trial tests) or minor tests (i.e. monthly tests). P3Q shared her view on this.

P3Q: Here, all teachers are asked to set the whole paper. Our Form 3, all tests have two papers, Paper 1 and Paper 2. We don't have single paper test 
like the other Forms. Well, we can still discuss with other teachers if you need to.

From the interview, $17 \%(n=12)$ of the teachers were assigned to prepare parts of the papers. It was either Paper 1 or Paper 2 of the whole test paper especially for major tests such as mid-term and final examination. P2F explained how the division was done in her school:

P2F: Normally two teachers are in-charge to set test papers for major tests like mid-term and final. So, among us, we divide the tasks. I do (set questions for) Paper 1 and she do (set questions for) Paper 2.

The remaining $7 \%(n=5)$ of the teachers prepared sections of a paper such as the grammar section or the essay section. Those who were assigned to prepare sections of paper were primarily those who prepared a test in groups.

P1E: I do sections of a paper since we have several teachers preparing one test. I am mostly involved in preparing 2 to 3 sections.

P3K: Since I prepare a test with my fellow colleagues, we divide the tasks according to sections. One person takes several sections to work on then we combine to form a full test.

Thus, in terms of task delegation, the teachers were usually assigned by their head of English panel to prepare whole test papers, which they prepared individually.

\section{Content decision}

After asking the teachers on task delegation, they were requested to provide feedback on how they prepared the content of a test. The data on who decided on the contents are illustrated in Figure 4.

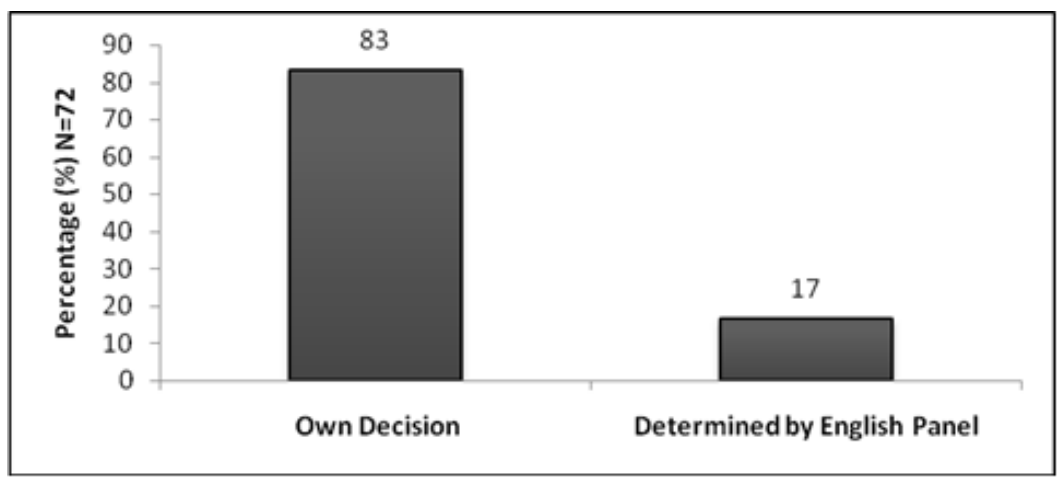

Figure 4. Decision on test content 
Based on the findings, $83 \%$ ( $n=60)$ of the teachers stated that they decided on the test content based on their own judgement while the remaining $17 \% \quad(n=12)$ mentioned the content was usually assigned by the English panel.

P1C: I decide the content on my own based on the resources available.

P2U: On my own [on deciding the content]. I make decision on what should be included and what should not.

P3F: In our school, what should be covered in a test is predetermined by the English panel. We are told to follow the required content during test preparation.

Interestingly enough, as revealed by $\mathrm{P} 1 \mathrm{C}$ and $\mathrm{P} 2 \mathrm{U}$, teachers were allowed to decide the test content based on their own considerations. In relation to this, the teachers elaborated on the types of test content that they included in a particular test as presented in Figure 5.

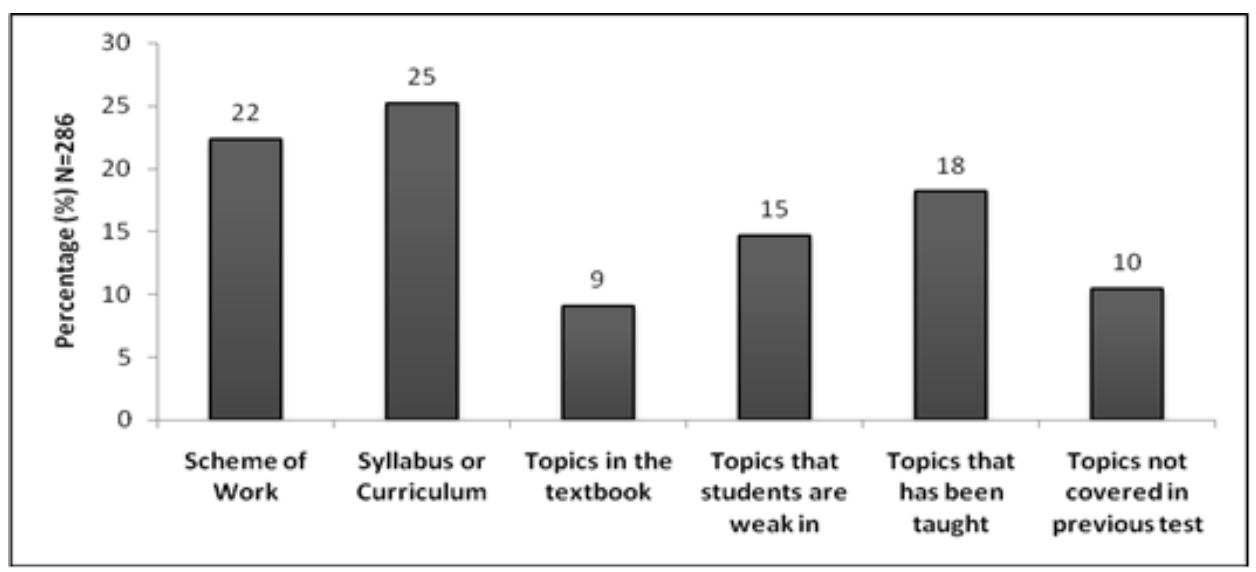

Figure 5. Types of test content included

Generally, the teachers included different types of test content.While all teachers claimed that the content was determined from the subject's syllabus (25\%, $\mathrm{n}=72$ ), a majority of them claimed the content was derived from their respective school's scheme of work $(22 \%, n=64)$. However, only $9 \%$ of the teachers $(n=26)$ stated that the content was taken from topics in the textbook. P1R and P2L explained why topics in the textbooks were not included.

P1R: Topics in the textbook are used for teaching. So, the topics would be too familiar for the students and they might do well, which may not provide a good indicator of their performance. 
P2L: I don't think the topics in the textbook are appropriate to be used as content of a test. For teaching, yes, but for testing, no.

It can therefore be concluded that teachers usually follow the syllabus and scheme of work in deciding which content should be included in a test.

\section{Guidelines selection}

Necessary references on how to prepare a test can help teachers prepare a better test that could address an intended purpose. Hence, the teachers were asked to provide input on the sources that they referred to when preparing a test paper (as shown in Figure 6).

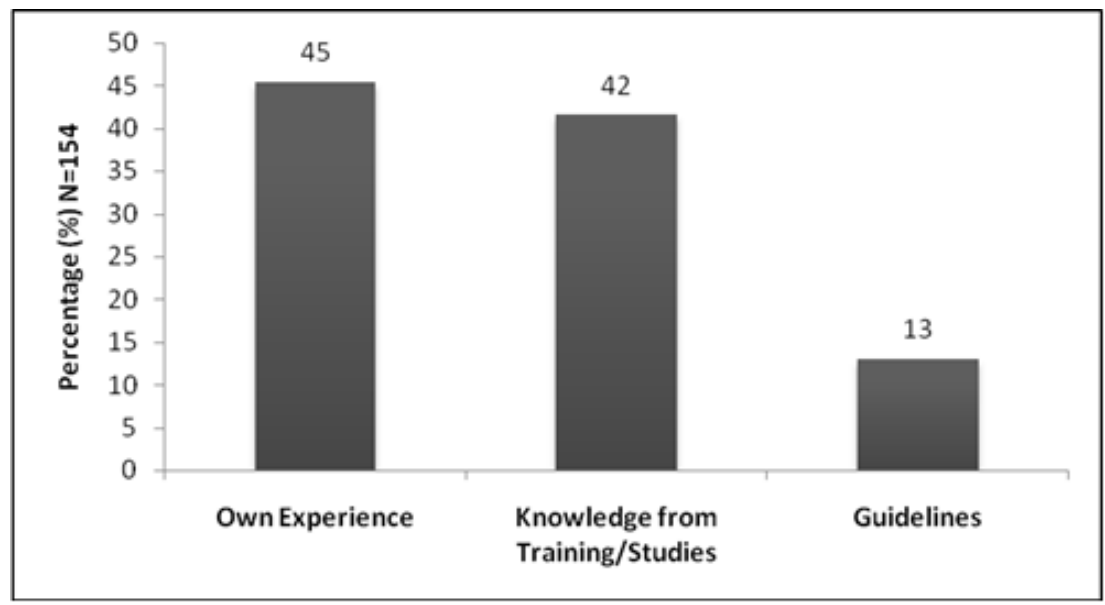

Figure 6. References used when preparing a test

The teachers stated that they relied heavily on their own experiences in teaching and test construction when preparing a test $(45 \%, n=70)$. P1A and P2C echoed this sentiment in the following excerpts:

P1A: The main source is still my own experiences. I have prepared a test for many times in my 8 years of teaching, so I feel more confident even without guidelines.

P2C: Of course, my own experience is the major source. I think most teachers would agree on this. Previous experience in test preparation does help.

Clearly, they both relied on their experiences in preparing a test, perhaps due to their years of service. 
Besides that, $13 \%(n=20)$ of the teachers mentioned the usage of guidelines provided by the school and the ministry (known as Jadual Penentuan Ujian or JPU) as their reference. JPU is a table that assists teachers to set questions or test items according to the levels in Bloom's Taxonomy (Krathwohl, Bloom, \& Masia, 1964), from the knowledge level to evaluation level. Teachers who set test papers have to plot the JPU table in order to balance the level of difficulty for the questions.

P2B: For major tests like final and trial tests, there is a need to follow the guidelines since it's of higher stake and we are advised to follow the ministry's JPU.

P3H: My school has a test preparation guideline or manual. We are told to use it whenever we prepare a test.

Excerpts from P2B and P3H show the teachers' awareness on the importance of following the guidelines. In addition, the teachers also mentioned the knowledge they gained from training and studies $(42 \%, n=64)$ as their source of reference.

P1R: I also refer to the knowledge I gained during my study in the university. I did take assessment-related courses. Plus, I also obtained knowledge from in-house training.

P2S: I attended a training course on assessment before. So I do refer to the knowledge gained from the training during test preparation as well.

P2S: I am studying a bachelor degree on PJJ (distance learning mode) now and there are two courses related to assessment. I learned a lot from these courses and it helps me to prepare the test.

To illustrate this clearly, the teachers' $(n=64)$ elaborations on where they obtained the knowledge is presented in Figure 7.

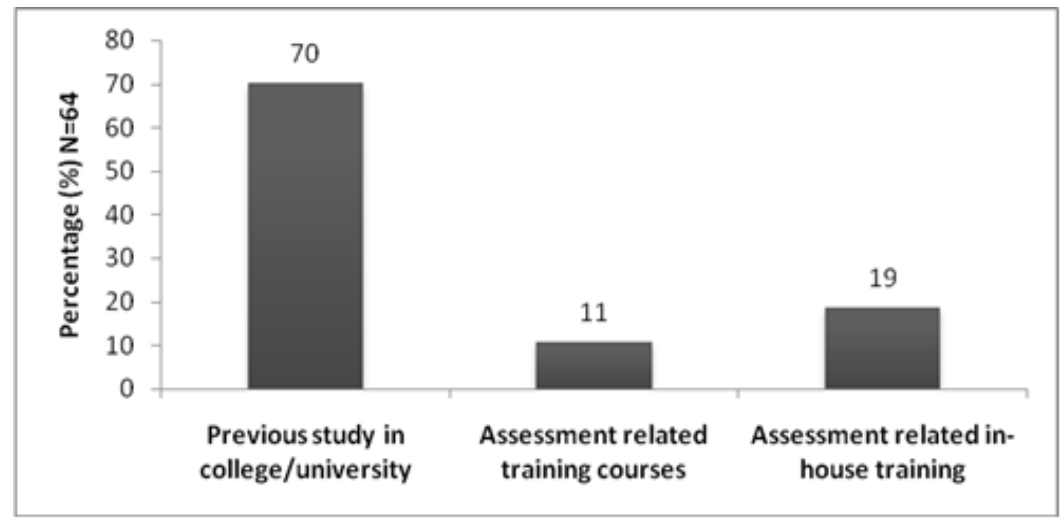

Figure 7. Knowledge sources when preparing a test 
As shown in Figure 7, during test preparation, the teachers relied on the knowledge they gained from their previous study in college and university $(70 \%, n=45)$, followed by in-house training provided $(19 \%, n=12)$. Unfortunately, very few of them $(11 \%$, $\mathrm{n}=7$ ) had the opportunity to participate in such training courses. Besides, there were also cases in which the teachers did not gain useful input from the courses that they attended simply because they were unable to grasp what had been delivered. As a result, they practised what they were more comfortable with.

P2M: Though I did attend the test item construction course (assessmentrelated course) but when preparing the test paper, I still rely on my knowledge gathered from my training college and previous experiences because I am more comfortable with it. Besides, I don't gain much from the course.

P3K: I have not got the opportunity to attend any assessment-related training but sometimes my colleagues share via in-house programmes, which I think is good.

The excerpts from P2M and P3K revealed the lack of training in assessments which usually prompted the teachers to make their own judgements in preparing test items. As pointed out by Mertler (2005), it also indicates the lack of assessment literacy among the teachers, which can lead to the case of "the blind leading the blind".

\section{Resource selection}

Next, the teachers were asked about the resources that they used in preparing a test. This is shown in Figure 8.

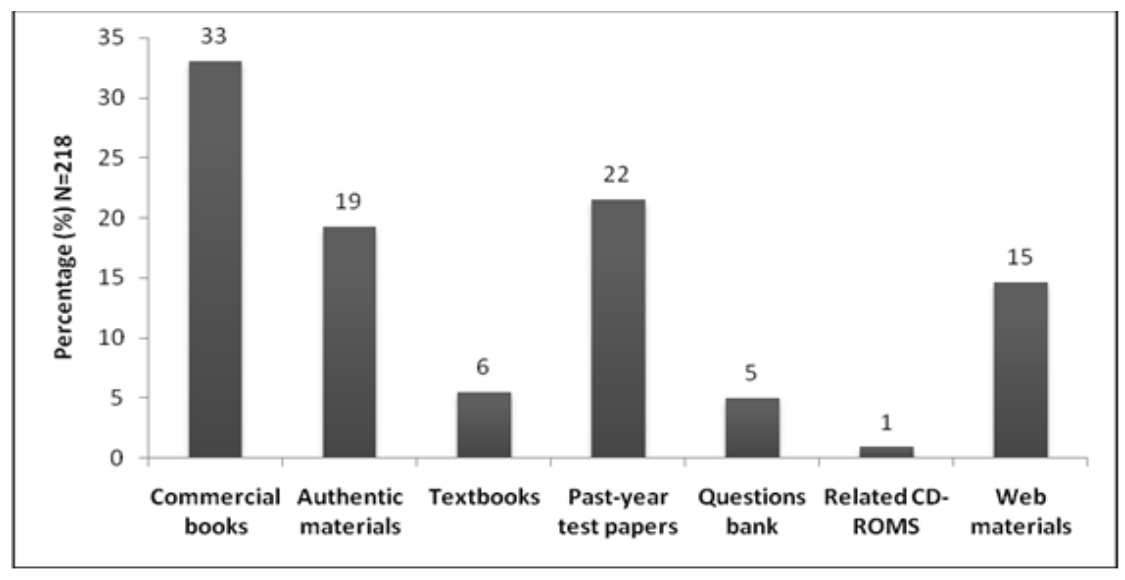

Figure 8. Resources used in test preparation

Commercial books and past-year test papers were the most used resources (33\%, $n=72)$. Meanwhile, textbooks $(6 \%, n=12)$, question banks $(5 \%, n=11)$ and language- 
related CD-ROMs $(1 \%, \mathrm{n}=2)$ were among the least used. Authentic materials such as newspaper articles and magazine $(19 \%, n=42)$ and web-based materials $(15 \%, n=32)$ were also popular resources. Commercial books especially by well-known authors were often used as teachers' main resource. Excerpts from four teachers illustrate this point.

P1A: I use commercial books a lot particularly from good authors. They have vast experience in setting questions for major exams, so following them would be a good way to learn.

P2J and P3I, on the other hand, stated time saving as a factor that drives them to use commercial books and past-year test papers.

P2J: It's more convenient and time saving to use commercial books and past-year test papers. I don't have to crack my head generating questions for each test.

P31: Obviously, using commercial books save me a lot of time. Instead of spending time looking for other resources, these books (showing a few books on her desk) help me to come up with a test paper much faster.

In this study, it is noted that very few schools have their own question banks. Only $5 \%$ of the teachers $(n=11)$ stated that they used question banks as one of their resources for test preparation. One of them is $\mathrm{P} 2 \mathrm{~K}$.

P2K: We have question banks for English, compiled by our teachers and kept by our head of English panel. Teachers, like me, can access to the compilation and refer. The questions or test papers are collected throughout Malaysia.

To further understand why a resource was chosen, the teachers were asked to state the reasons for the selection of a resource.

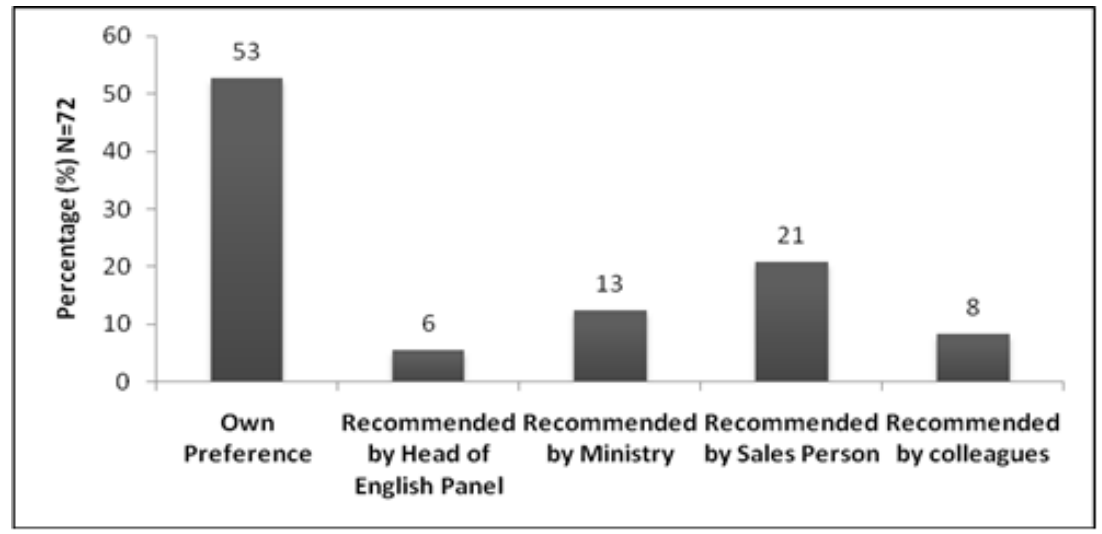

Figure 9. Reasons for choosing a resource 
As shown in Figure 9, the primary reason was the teachers' own preference (58\%, $n=38)$. This was followed by recommendations from sales persons $(21 \%, n=15)$. This finding is rather expected since the main resource chosen by the teachers was commercial books. The teachers were noted to be less influenced by the resources as recommended by the head of English panel $(6 \%, n=4)$ and their colleagues (8\%, $\mathrm{n}=6)$. After knowing the process of selecting resources, the teachers were asked about the final stage of test preparation which is finalisation.

\section{Finalisation}

Finalisation refers to the endorsement process that teachers need to go through after they have prepared a test. It is mainly to identify whether the process is strict or lenient according to different test types. A finalisation process is considered strict when teachers are required to follow standardised procedures as set by the school or the English panel. On the contrary, it is considered lenient if teachers are given the freedom to decide. Figure 13 illustrates the findings.

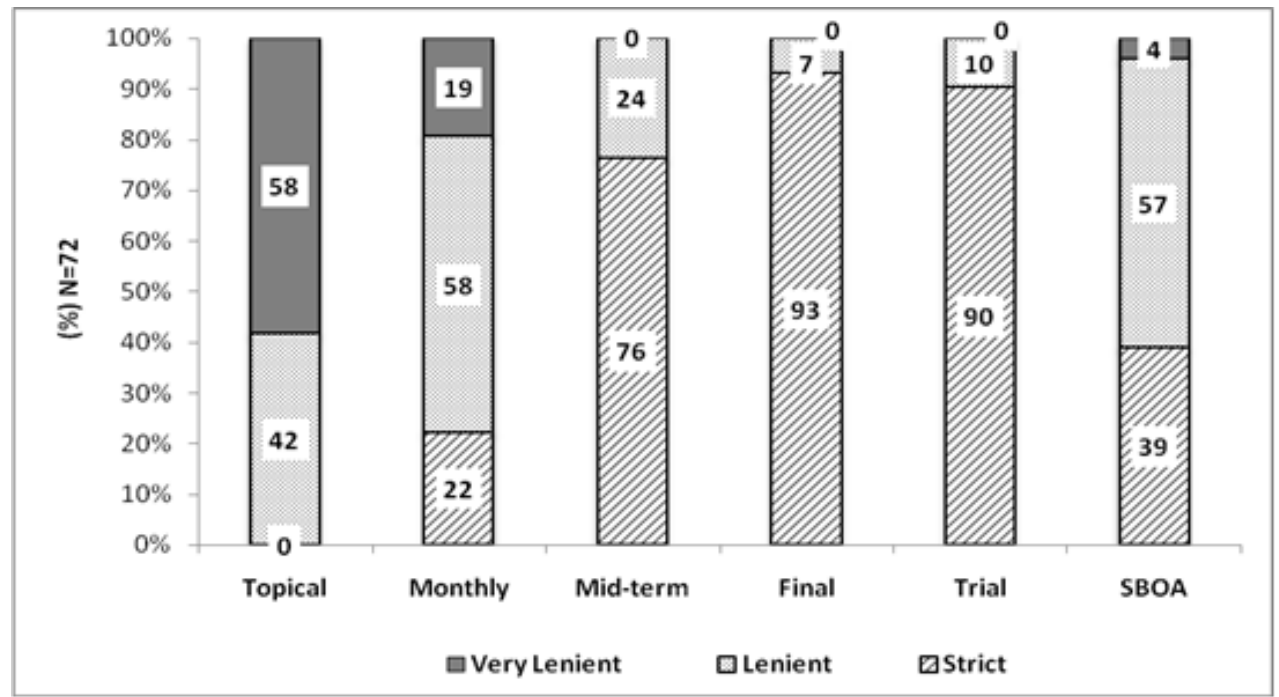

Figure 10. Level of strictness in finalising a test paper

As shown in Figure 13, the process of finalising a test paper was stricter for mid-term $(76 \%, n=55)$, final $(93 \%, n=67)$ and trial tests $(90 \%, n=65)$. This could be due to its high importance in addressing school accountability since the results from these tests would be used indicators of school's performance. P2J and P3V shared their opinions on this matter:

P2J: For high-stake tests like final, we do follow rigid procedures in finalising a test paper that has been prepared. We need to submit the draft to the head of English panel for endorsement and then the senior assistant or the principal need to check and approve the test paper before it can be 
administered. I think this is to ensure the standard is there, before it will affect the school's reputation.

P3V: In terms of finalising the test papers for final and trial, it is not that simple or lenient. The head of English panel wants us to make sure we have followed the guidelines before she will allow it to be used. I think this is good because it enhance the quality of the test paper.

Progress-based tests such as topical and monthly tests were found to be lenient in terms of the finalisation process. A total of $58 \%(n=42)$ of the teachers mentioned that the finalisation of topical test was very lenient while the remaining $42 \%(n=30)$ stated it as less rigid. As for monthly tests, $19 \%(n=14)$ of the teachers claimed the finalisation process to be very lenient while another $58 \%(n=42)$ stated it as less rigid. Test papers prepared for such tests were normally not cross-checked by the head of English panel or senior assistants as mentioned by P1U, P2F and P3C:

P1U: Monthly tests are not so rigid. Our head (of English panel) will not check or endorse the test papers that we have prepared. It is up to us to decide.

P2F: Finalising monthly tests are less rigid. As I told you, the school regards the tests as not that important, hence we don't have to go for meetings or double check before it can be administered.

P3C: My school doesn't require us to finalise a monthly test paper. There is no need for endorsement or approval from the senior assistant. We just go ahead once it is ready.

Thus, as revealed in the excerpts, it is evident that the process of finalising a test paper is stricter in achievement-based tests thanto progress-based tests. This is due to the level of importance of each test as determined by the school.

\section{Conclusion}

This paper reports the English language teachers' practices in preparing a test in lower-secondary school. In summary, the findings of the study showed that teachers were essentially assigned to prepare a test individually with minimal interference from the English panel or other related parties. In terms of content, the teachers had a tendency of following the school's syllabus and scheme of work. Unlike teachers' dependency on textbooks in schools in Canada and China (as reported by Cheng et al., 2004), the present study revealed teachers' high reliance on commercial books in helping them to prepare the content for various tests. Textbooks, on the other hand, were rarely used. This is similar to the findings by Leung and Andrews (2012), who found that teachers in Hong Kong rarely depend on textbooks when preparing high-stakes exams as they were encouraged to develop 
their own materials or test items specifically for school-based assessments. In this study, the teachers also relied on their own experience in deciding how to a test should be prepared. Lastly, in terms of finalisation, endorsements were compulsory for major tests such as mid-term and final tests and the process was less rigid for topical and monthly tests.

From this study, it is recommended that teacher development in assessment should be promoted and carried out in a more frequent manner. It is apparent that teachers still lack theoretical understanding of what constitutes good assessment practices. Professional development is thus crucial in ensuring that teachers are well-equipped with related knowledge that would assist them in conducting assessment. In addition, a more comprehensive guideline covering assessments for both progress- and achievement-based purposes is urgently needed. As indicated in this research, a majority of the teachers tend to practise what they think is right with no proper guideline to rely on as reference. The Ministry of Education could devise an assessment framework in line with the curriculum framework that aims at promoting teaching and student learning, beyond the confinement of pointing out what are covered in the public examinations.

\section{References}

Airasian, P. W. (2005). Classroom assessment: Concepts and applications (5th ed.). Boston, MA: McGraw-Hill.

Bailey, K. M. (2004). Learning about language assessment: Dilemmas, decisions and directions. Boston, MA: Heinle \& Heinle Publishers.

Black, P., \& Wiliam, D. (1998). Assessment and classroom learning. Assessment in Education: Principles, Policy \& Practice, 5(1), 7-68.

Cheng, L., Rogers, T., \& Hu, H. (2004). ESL/EFL instructors' classroom assessment practices: Purposes, methods, and procedures. Language Testing, 21(3), 360-389.

Cizek, G., \& Fitzgerald, S. (1996). Teachers' assessment practices: Preparation, isolation, and the kitchen sink. Educational Assessment, 3(2), 159-179.

Cumming, A. (2001). ESL/EFL instructors' practices for writing assessment: Specific purposes or general purposes? Language Testing, 18, 207-24.

Guskey, R. T., \& Bailey, M. J. (2001) Developing grading and reporting systems for student learning. Thousand Oaks, CA: Corwin Press.

Krathwohl, D.R., Bloom, B.S., and Masia, B.B. (1964). Taxonomy of educational objectives: Handbook II: Affective domain. New York, NY: David McKay Co.

Khemlani-David, M. (1992). Lessons learnt from vetting English examination papers. The English Teacher, 21. Retrieved from: http://www.melta.org.my/ ET/1992/main10.html

Leung, C. Y., \& Andrews, S. (2012). The mediating role of textbooks in high-stakes assessment reform. ELT Journal, 66(3), 356-365.

Lee, J. W. (2009). How do teachers assess students in their English language classrooms? The Journal of Studies in Language, 25(1), 141-162.

Malone, M. E. (2013). The essentials of assessment literacy: Contrasts between testers and users. Language Testing, 30(3), 329-344. 
Mertler, C. (2005). Secondary teachers' assessment literacy: Does classroom experience make a difference?. American Secondary Education, 33(2), 76-92.

Poskitt, J., \& Mitchell, K. (2012). New Zealand teachers' overall teacher judgements (OTJs): Equivocal or unequivocal?. Assessment Matters, 4, 53-75.

Rea-Dickins, P. (2004). Understanding teachers as agents of assessment. Language Testing, 21(3), 249-258.

Smith, R. (2001). Formative evaluation and the scholarship of teaching and learning. New Directions for Teaching and Learning, 88, 51-62.

Vengadasamy, R. (2002). Responding to student writing: Motivate, not criticise. GEMA Online Journal of Language Studies, 2(1), 191-219.

Yueming, J., Eslami, Z. R., \& Burlbaw, L. M. (2006). ESL teachers' perceptions and factors influencing their use of classroom-based reading assessment. Bilingual Research Journal, 30(2), 407-430. 